\title{
Multiple Cerebral and Systemic Aneurysms in a Case of Left Atrial Myxoma - Are They Related?
}

\author{
Gaurav Chauhan ${ }^{1}$, Vivek Singh ${ }^{2}$, RV Phadke ${ }^{3}$, Sapna Yadav and Vikas Aggarwal ${ }^{5}$ \\ ${ }^{1}$ Department of Radiology, Senior Resident, PDCC Neuroradiology, SGPGIMS, Lucknow, Uttar Pradesh, India \\ ${ }^{2}$ Department of Radiology, Associate Professor, Radiology Department, SGPGIMS, Lucknow, Uttar Pradesh, India \\ ${ }^{3}$ Department of Radiology, Professor and Head, Radiology Department, SGPGIMS, Lucknow, Uttar Pradesh, India \\ ${ }^{4}$ Department of Anaesthesia, Senior Resident, PDCC Neuroanaesthesia, SGPGIMS, Lucknow, Uttar Pradesh, India \\ ${ }^{5}$ Department of Immunology, Professor, Department of Immunology, SGPGIMS, Lucknow, Uttar Pradesh, India
}

\section{Correspondence to: \\ Vivek Singh \\ Department of Radiology, Associate Professor \\ Radiology Department, SGPGIMS, Lucknow \\ Uttar Pradesh, India \\ Tel: 8004904503 \\ E-mail: singhvivek79@rediffmail.com}

Received: March 13, 2019

Accepted: May 16, 2019

Published: May 20, 2019

Citation: Chauhan G, Singh V, Phadke RV, Yadav S, Aggarwal V. 2019. Multiple Cerebral and Systemic Aneurysms in a Case of Left Atrial Myxoma - Are They Related? J Neuroimaging Psychiatry Neurol 4(1): 12-14.

Copyright: () 2019 Chauhan et al. This is an Open Access article distributed under the terms of the Creative Commons Attribution 4.0 International License (CC-BY) (http://creativecommons. org/licenses/by/4.0/) which permits commercial use, including reproduction, adaptation, and distribution of the article provided the original author and source are credited.

Published by United Scientific Group

\begin{abstract}
Cardiac myxomas are known to be associated with cerebral aneurysms, however the mechanism of aneurysm formation is still debatable. Myxomatous tumor emboli to the vessel wall have been propounded as the plausible mechanism for aneurysm formation. Recent literature also implicates raised interleukin-6 (IL6), secreted by atrial myxomas, in the genesis of aneurysms. We describe a patient who presented with mild persistent headache, later diagnosed to be harbouring multiple unruptured cerebral and systemic aneurysms. Our case highlights the importance of radiological modalities in timely diagnosis of myxoma with its cerebral and systemic embolic complications.
\end{abstract}

\section{Keywords}

Atrial myxoma, Aneurysm, Angiography, Interleukin-6

\section{Introduction}

Cardiac myxoma is a mesenchymal tumour and is the most common primary cardiac neoplasm [1]. As it usually arises in left atrium, systemic emboli from myxoma can spread to both cerebral and systemic vasculature, lead to ischemic, haemorrhagic complications and rarely aneurysms formation [2-4]. Aneurysms associated with myxomas are usually multiple, fusiform and peripheral [5, 6]. The embolization of tumor particles to vessel wall has been ascribed in weakening of subintimal tissue resulting in aneurysm formation [7]. Recent reports have also implicated the role of IL-6 in aneurysm genesis in patients harbouring atrial myxomas. IL-6 is a pro-inflammatory cytokine that has also been implicated in the development of cerebral aneurysms $[8,9]$. Neurological manifestations in a patient presenting initially, may lead to discovery of primary tumor i.e. cardiac myxoma in the course of investigations and diagnosis, as in our case. We report a case of an adult male presenting with headache. Imaging and angiography revealed multiple cerebral \& systemic aneurysms along with left atrial myxoma on echocardiography.

\section{Case Report}

A 38-year-old adult male patient presented with complain of intermittent headache. NCCT (Figure 1a) and CECT (Figure 1b) were done, which showed iso to hyperdense globular lesions along bilateral sylvian fissures and other sulcal 
spaces showing homogenous post contrast enhancement. MRI was done for further evaluation, showing corresponding T1 hyperintensity (Figure 1c) and T2 hypointensity (Figure 1d) within the lesions with homogenous post contrast enhancement (Figure 1e) raising the suspicion for vascular lesions. Patient was posted for diagnostic cranial angiography using biplane digital subtraction angiography (DSA). Angiography (Figure $1 \mathrm{f}-\mathrm{j}$ ) showed numerous (upto 20) globular and fusiform outpouchings and focal vascular ectatic segments in bilateral anterior and posterior circulation suggestive of aneurysms. To rule out the possibility of mycotic aneurysm from valvular vegetations, echocardiography was

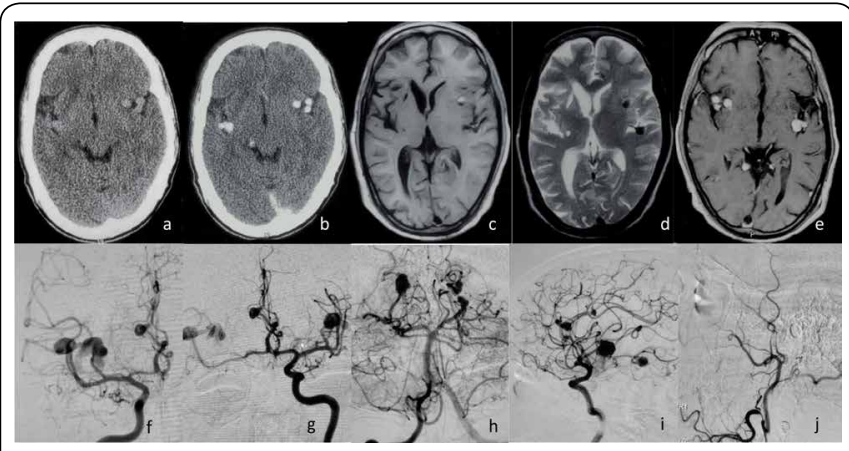

Figure 1: $\operatorname{NCCT~(a)~shows~few~iso~to~hyperdense~globular~lesions~}$ along bilateral sylvian fissures, showing intense enhancement in CECT (b). MRI scan shows focal T1 hyperintensity (c) and T2 hypointensity (d) within the lesions with intense post contrast enhancement (e). DSA images shows multiple aneurysms $(\mathrm{f}-\mathrm{i})$ in bilateral anterior and posterior vasculature (bilateral ICA and vertebral arteries. Bilateral ECA runs are normal $(j-$ right ECA)

done. Echocardiography (Figure 2a) showed a large broad based $\sim 4.8 \times 3.4 \mathrm{~cm}$ sized homogenously echogenic lesion in left atrium. CT angiography was done to rule out any systemic complications. CT angiography shows a large hypoenhancing mass in left atrium (Figure 2b), few (upto 3) peripheral hepatic artery aneurysms (Figure 2c), distal superior mesenteric artery branch aneurysm (Figure 2c) and single left renal artery aneurysm at hilum (Figure 2d). Surprisingly the patient had normal serum IL-6 levels $(6 \mathrm{pg} / \mathrm{ml})$, as opposed to many literature documentations.

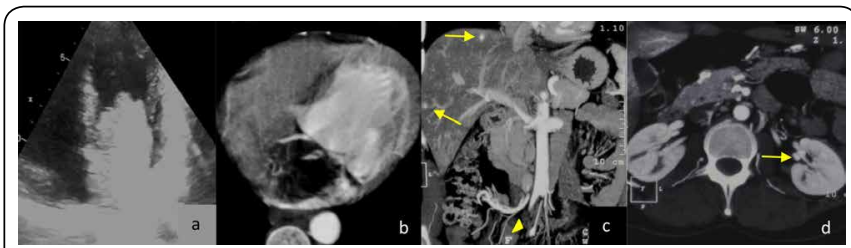

Figure 2: Echocardiography (a) shows a large sessile echogenic mass lesion in left atrium. CTA showed a large hypoenhancing mass lesion in the left atrium (b), few small aneurysms (arrows) in the distal branches of hepatic artery, distal branch of (arrowhead) superior mesenteric artery (c) and left renal artery near hilum (d)

\section{Discussion}

Cardiac myxoma is a mesenchymal tumor and accounts for half of all primary cardiac neoplasms, predominantly in (75\%) left atrium [10]. Patients with cardiac myxoma usually presents with cardiac (60\%), constitutional and embolic symptoms. Constitutional symptoms include anemia, weight loss, fever, elevated erythrocyte sedimentation rate, hypergammaglobulinemia and leukocytosis. Cardiac symptoms can be ascribed to impediment of myocardial function by left atrial tumor and comprise of dyspnea, palpitations and syncope [11]. Due to their proclivity for left atrium, systemic embolism is quite common. The neurological signs and symptoms in a patient of left atrial myxoma results from embolization, out of which cerebral ischemic \& haemorrhagic changes, brain parenchymal metastasis and oncotic aneurysm formation are most common [12]. Ischemic infarcts due to vascular occlusion from embolised myxomatous particles have also been documented in various literature reports [13, 14]. First case of cerebral aneurysm associated with cardiac myxoma was reported by Stoane et al. [15]. Cerebral aneurysms can be diagnosed with CT and MRI angiographies, but catheter angiography is gold standard. Cerebral vascular aneurysms associated with myxoma are usually fusiform (may have saccular element) and peripherally located [16].

Cerebral aneurysmal dilatations and vessel irregularities in patients of cardiac myxomas have been linked to neoplastic properties of a myxoma and embolism of tumor particles to vessel wall. The embolic oncotic particles deposit in the vessel wall, penetrate the vasa vasorum, causing weakening, ectasia and aneurysmal dilatation of vessel wall as has been demonstrated by various studies $[17,18]$.

Many studies have supported the fact that atrial myxoma cells are capable of producing IL-6. IL-6 is a cytokine which causes differentiation \& proliferation of cells along with overexpression of several proteolytic enzymes that degrade extracellular matrix (ECM), promoting fragmentation of tumor and acceleration of embolic event. Formation of cerebral aneurysm may be related to overproduction of IL-6 by tumor emboli causing degradation of ECM in cerebral vessels [1921].

Available literature suggests that the treatment of choice for atrial myxomas is surgical removal. Surgery should be conducted at the earliest so as to prevent the possible risk of further tumour embolism, cardiac valve obstruction and improving the cardiac function. Few literary evidences have also suggested presumably decreased number and size of aneurysms following myxoma resection. However, myxoma resection does not eliminate the risk of delayed aneurysm formation regardless the mechanism of development either by embolization or metastasis [22]. For this reason, followup monitoring for the development of aneurysms, using non-invasive imaging (MRI/MRA) is recommended after intervention for myxoma resection [23]. No definitive treatment has been advised, as of now, for aneurysms due to cardiac myxomas except for active observation.

Our patient has been under follow up of cardiac surgery department for atrial myxoma, under interventional neuroradiology and neurosurgery department for intracranial aneurysms. Up to recent OPD follow up, patient has been stable, been advised for myxoma resection and detailed about the prognosis. For size and numbers of intracranial aneurysms the patient is being followed up with MRA every 6 months 
under neurosurgery and neuro radiology department.

Multimodality radiological evaluation should be done in the patients presenting with multiple cerebral aneurysms, especially echocardiography to rule out the mycotic (valvular vegetations) or oncotic (atrial myxoma) etiologies and angiography (CTA, MRA or catheter angiography) to define the location and number of cerebro-systemic aneurysms. Patients with multiple cerebral aneurysms should routinely be assessed for cardiac myxoma and vice-versa.

\section{References}

1. MacGowan SW, Sidhu P, Aherne T, Luke D, Wood AE, et al. 1993. Atrial myxoma: national incidence, diagnosis and surgical management. Ir J Med Sci 162(6): 223-226. https://doi.org/10.1007/BF02945200

2. Nucifora PG, Dillon WP. 2001. MR diagnosis of myxomatous aneurysms: report of two cases. AJNR Am J Neuroradiol 22(7): 13491352.

3. Sabolek M, Bachus-Banaschak K, Bachus R, Arnold G, Storch A. 2005. Multiple cerebral aneurysms as delayed complication of left cardiac myxoma: a case report and review. Acta Neurol Scand 111(6): 345-350. https://doi.org/10.1111/j.1600-0404.2005.00413.x

4. Herbst M, Wattjes MP, Urbach H, Inhetvin-Hutter C, Becker D, et al. 2005. Cerebral embolism from left atrial myxoma leading to cerebral and retinal aneurysms: a case report. AJNR AmJ Neuroradiol 26(6): 666669.

5. Tamuleviciute E, Taeshineetanakul P, Terbrugge K, Krings T. 2011. Myxomatous aneurysms: a case report and literature review. Interv Neuroradiol17(2):188-194.https://doi.org/10.1177/159101991101700208

6. Oguz KK, Firat MM, Cila A. 2001. Fusiform aneurysms detected 5 years after removal of an atrial myxoma. Neuroradiology 43(11): 990992. https://doi.org/10.1007/s002340100614

7. Furuya K, Sasaki T, Yoshimoto Y, Okada Y, Fujimaki T, et al. 1995. Histologically verified cerebral aneurysm formation secondary to embolism from cardiac myxoma. Case report. J Neurosurg 83(1): 170173. https://doi.org/10.3171/jns.1995.83.1.0170

8. Saji T, Yanagawa E, Matsuura H, Yamamoto S, Ishikita T, et al. 1991. Increased serum interleukin-6 in cardiac myxoma. Am Heart J122(2): 579-580. https://doi.org/10.1016/0002-8703(91)91022-F

9. Morgan L, Cooper J, Montgomery H, Kitchen N, Humphries SE. 2006. The interleukin-6 gene $-174 \mathrm{G}>\mathrm{C}$ and $-572 \mathrm{G}>\mathrm{C}$ promoter polymorphisms are related to cerebral aneurysms. J Neurol Neurosurg Psychiatry 77(8): 915-917. https://doi.org/10.1136/jnnp.2005.081976

10. Hung PC, Wang HS, Chou ML, Huang SC, Su WJ. 1992. Multiple cerebral aneurysms in a child with cardiac myxoma.J Formos Med Assoc 91(8): 818-821.
11. Reynen K. 1995. Cardiac myxomas. N Engl J Med 333(24): 1610-1617. https://doi.org/10.1056/NEJM199512143332407

12. Chen HJ, Liou CW, Chen L. 1993. Metastatic atrial myxoma presenting as intracranial aneurysms with hemorrhage. Surg Neurol 40(1): 61-64. https://doi.org/10.1016/0090-3019(93)90173-X

13. Hatayama S, Ogata T, Okawa M, Higashi T, Inoue T, et al. 2012. Ischemic stroke induced by a left atrial myxoma. Brain Nerve 64(10): 1175-1179. https://doi.org/10.11477/mf.1416101323

14. Ise H, Ishikawa N, Nakanishi S, Kamiya H. 2018. Giant left atrial myxoma causing acute ischemic stroke in a child. Surg Case Rep 4: 6. https://doi.org/10.1186/s40792-017-0411-2

15. Sloane L, Allen JH, Collins HA. 1996. Radiologic observations in cerebral embolisation from left heart myxoma. Radiology 87(2): 262266. https://doi.org/10.1148/87.2.262

16. Yilmaz MB, Akin Y, Guray U, Kisacik HL, Korkmaz S. 2003. Late recurrence of left atrial myxoma with multiple intracranial aneurysms. Int J Cardiol 87(2-3): 303-305. https://doi.org/10.1016/S01675273(02)00348-0

17. New PF, Price DL, Carter B. 1970. Cerebral angiography in cardiac myxoma: correlation of angiographic and histopathologic findings. Radiology 96(2): 335-345. https://doi.org/10.1148/96.2.335

18. Rodriguez FJ, Brown RD, Mohr JP, Piepgras DG, Thielen K, et al. 2006. Embolic atrial myxoma with neoplastic aneurysm formation and haemorrhage: a diagnostic challenge. Neuropathol Appl Neurobiol 32(2): 213-216. https://doi.org/10.1111/j.1365-2990.2006.00721.x

19. Koo YH, Kim TG, Kim OJ, Oh SH. 2009. Multiple fusiform cerebral aneurysms and highly elevated serum interleukin-6 in cardiac myxoma. J Korean Neurosurg Soc 45(6): 394-396. https://doi.org/10.3340/ jkns.2009.45.6.394

20. Orlandi A, Ciucci A, Ferlosio A, Pellegrino A, Chiariello L, et al. 2005. Increased expression and activity of matrix metalloproteinases characterize embolic cardiac myxomas. Am J Pathol 166(6): 1619-1628. https://doi.org/10.1016/S0002-9440(10)62472-8

21. Wada A, Kanda T, Hayashi R, Imai S, Suzuki T, et al. 1993. Cardiac myxoma metastasized to the brain: potential role of endogenous interleukin-6. Cardiology 83(3): 208-211. https://doi. org/10.1159/000175971

22. Walker MT, Kilani RK, Toye LR, Bird CR. 2003. Central and peripheral fusiform aneurysms six years after left atrial myxoma resection. $J$ Neurol Neurosurg Psychiatry 74(2): 281-282. https://doi.org/10.1136/ jnnp.74.2.281

23. Stöllberger C, Finsterer J. 2008. Patients with cardiac myxoma require surveillance for myxoma-related cerebral aneurysms. Eur I Neurol 15(12): e110-e111. https://doi.org/10.1111/j.1468-1331.2008.02298.x 